The University of Maine

DigitalCommons@UMaine

Earth Science Faculty Scholarship

Earth Sciences

$3-1982$

\title{
Source and climatic implication of the reactive iron and reactive silicate concentration found in a core from Meserve Glacier, Antartica
}

\author{
Paul Andrew Mayewski \\ University of Maine, paul.mayewski@maine.edu \\ William Berry Lyons
}

Follow this and additional works at: https://digitalcommons.library.umaine.edu/ers_facpub

Part of the Glaciology Commons, and the Hydrology Commons

\section{Repository Citation}

Mayewski, Paul Andrew and Lyons, William Berry, "Source and climatic implication of the reactive iron and reactive silicate concentration found in a core from Meserve Glacier, Antartica" (1982). Earth Science Faculty Scholarship. 186.

https://digitalcommons.library.umaine.edu/ers_facpub/186 
GEOPHYSICAL RESEARCH LETTERS, VOL. 9, No. 3, PAGES 190-192, MARCH 1982

SOURCE AND CLIMATIC IMPLICATION OF THE REACTIVE

IRON AND REACTIVE SILICATE CONCENTRATION

FOUND IN A CORE FROM MESERVE GLACIER, ANTARTICA

Paul A. Mayewski and Wm. Berry Lyons

Department of Earth Sciences, University of New Hampshire, Durham, NH 03824

Introduction. Glaciochemistry has recently provided a useful tool in the study of snow accumulation rates (Herron and Langway, 1979; Bulter et al., 1980 Warburton and Young, 1981; Mayewski et al., in press) and the elucidation of long-term climatic change (Delmas et al., 1980; Thompson and Mosley-Thompson, 1981) as well as the definition of aerosol/precipitation source areas (Warburton and Linkletter, 1978). Recent glaciochemical work from Antarctica has suggested that although cations associated with seasalt ( $\mathrm{Na}, \mathrm{Mg}, \mathrm{Ca}$ and $\mathrm{K}$ ) decrease in concentration as one proceeds inland, crustally-derived chemical species such as $\mathrm{Al}$ and Fe remain relatively constant in snow and ice (Boutron and Martin, 1980; Herron and Langway, 1979; Johnson and Chamberlain, 1981; Warburton and Young, 1981). This paper presents the first data suggesting that there is in some cases a local source for the crustally-derived material that enters Antarctic precipitation.

\section{Drill Site}

Meserve Glacier $\left(77^{\circ} 35^{\prime} \mathrm{S}, 162^{\circ} 23^{\prime} \mathrm{E}\right)$ is a $7.2 \mathrm{~km}$ long, north-facing alpine glacier situated on the southern wall of Wright Valley, one of the major ice-free valleys of Southern Victoria Land, Antarctica. The total $9.9 \mathrm{~km}^{2}$ area of the glacier is devisible into an $8.1 \mathrm{~km}$ accumulation zone, elevation range $1200-1500 \mathrm{~m}$, and a $1.8 \mathrm{~km}^{2}$ ablation zone, elevation range 440-600 m (Bu11 and Carnein, 1970). During the 1979-1980 austral summer a $12.85 \mathrm{~m}$ core was extracted from the accumulation zone of this glacier, at an elevation of $1230 \mathrm{~m}$. Temperature measurements taken in the bore hole after it had equilibrated with the ice surrounding it revealed a temperature of $-27^{\circ} \mathrm{C}$ at $10 \mathrm{~m}$ depth which remained constant to the base of the hole. The coring operation was undertaken as a test to recover samples for calibrating and tuning analyses proposed for forthcoming work in Northern V1ctoria Land. Although several analyses were performed on the Meserve core results of only the iron and reactive slificate are presented here because in this case their source and variation down the core have implications with respect to the climatic history of the ice-free valleys.

\section{Sampling and Analytical Procedures}

A total of 65 samples was recovered from the core using a standard stainless steel SIPRE ice auger. The coring apparatus was cleaned thoroughly in distilled-deionized water prior to coring and wrapped in plastic while not in use. To alleviate contamination by the coring apparatus polyethylene

Copyright 1982 by the American Geophystcal Union. scrapers were used to remove the outer $1-2 \mathrm{~cm}$ of the total $8.5 \mathrm{~cm}$ diameter of each sample. Since the 1979 season we have converted to a Tefloncoated SIPRE auger and expect in future seasons to change to all plastic coring devices. Boutron (1979) has shown that clean metal augers can contaminate snow samples with Fe. However, due to the fact that $\mathrm{Fe}$ correlates so well with reactive silicate (fig. 1), the high Fe values are probably not due to contamination. All samples were handled with plastic gloves, sectioned and scraped with plexiglass scrapers in the field and placed in pre-cleaned, HCl washed plastic bags which were rinsed 4-5 times with distilled-deionized water. Once in the securely sealed bags the samples were allowed to melt. Sample densities were determined from volumes computed at the time of sample extraction and weights were measured after the samples had melted. Immediately upon melting the water was transferred to HCL-cleaned $125 \mathrm{ml}$ LPE bottles. Modified sample collection and handling techniques, such as the collection of frozen cores, have been employed in our more recent studies to further reduce contamination, but within the scope of this test study the 1979 techniques are believed to be suitable. Blank studies conducted on the plastic bags and bottles indicated a mean reactive iron blank of less than $0.1 \mu \mathrm{M}$ and a reactive silicate blank of $0.036 \mu \mathrm{M}$.

Upon return to our laboratories the melted samples were acidified with ultrapure $\mathrm{HNO}_{3}$ and allowed to set for at least 10 days. Reactive silicate was analyzed colorimetrically utilizing autoanalyzer techniques (Gilbert and Loder, 1977). Reactive iron was determined colorimetrically using the method of Stookey (1970). (Reactive silicate and reactive iron are defined as the silicate and iron in the nitric actd leachate that react with the color producing reagents. They should not to be regarded as 'total' values. The analytical precision of the reactive silicate and iron at the concentrations observed in these samples reported as a coefficient of variation is $\pm 8 \%$ for both species.

\section{Results and Discussion}

Down-core dȩnsity values (fig. la) ranged from $.42-.90 \mathrm{gm} \mathrm{cm}^{-3}$ although the firn-ice transition zone was never reached. From the ice surface to a depth of approximately $6.7 \mathrm{~m}$ densities rise gradually while below $6.7 \mathrm{~m}$ only a slight overall increase in density is observable. Reactive silicate (fig. lb) ranged from less than $0.05 \mu \mathrm{M}$ (trace) to $24.3 \mu \mathrm{M}$. Maxima in these values occur generally in the depth ranges 0 to $3.5 \mathrm{~m}$ and 7.5 to $10.3 \mathrm{~m}$. Iron values (fig. 1c) ranged from $0.36 \mu \mathrm{M}$ to $4.83 \mu \mathrm{M}$. Maxima in these values occur generally in the depth ranges 0 to $3.3 \mathrm{~m}$ and 7.3 to $10.1 \mathrm{~m}$. Visual comparison of the plots of density, reactive silicate and iron suggest no 

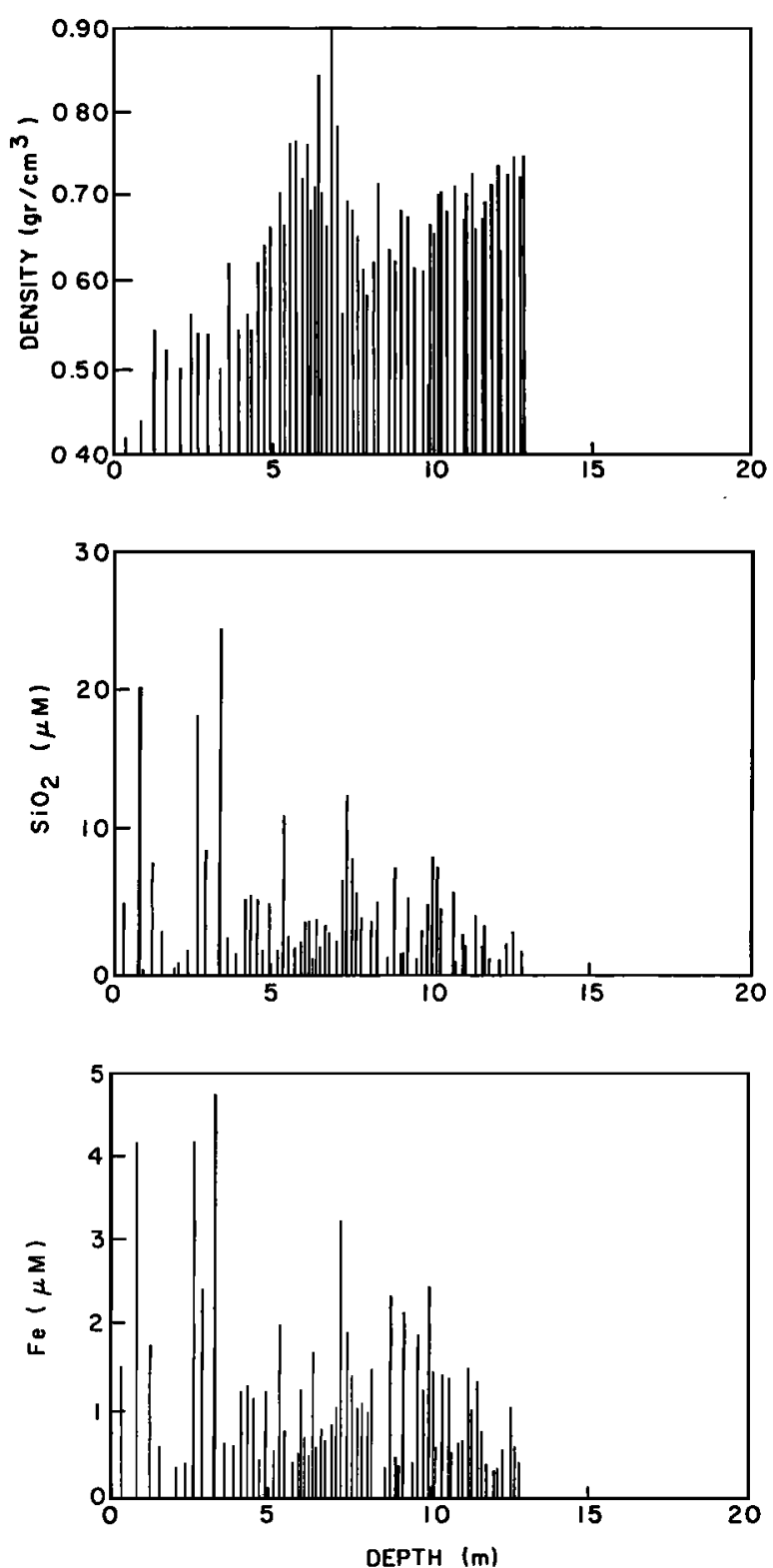

Figure la Down core values for density.

Figure 1b Down core values for reactive silicate.

Figure Ic Down core values for reactive Iron.

probable association of reactive silicate and/or iron with density but there appears to be a close spatial association between the distributions of reactive silicate and iron. Although the Meserve time-series is too short to unambiguosly assess cyclicity, analysis of the phase relationship, using cross spectral analysis, between the reactive silicate and reactive iron time-series suggest that these serles match to within $6 \%$ corroborating the visual examination. No discernible relationship can be identified between density and reactive silicate or reactive iron.

The reactive silicate and iron concentrations present in the Meserve core are presumed to be due to the influx of primarily continental aerosols derived most probably from within the ice-free valleys, the largest such local source in the region. By comparison, Ice analyses by Boutron et al., (1972), Boutron and Lorius, (1977, 1979) and Boutron and Martin (1980) in portions of East Antarctica such as Dome $C$, far from the ice-free valleys, yield much lower iron values than those observed by us. Their values range from 0.006 to $0.2 \mu \mathrm{M}$. Their studies can be used to support our contention that the majority of debris being deposited on Meserve Glacier is indeed probably derived from local sources. Unfortunately, to our knowledge, there is no silicate data available from Antarctic ice for comparison with our data.

The maxima in concentration of reactive silicate and iron occur at approximately the depth range $0-3.5 \mathrm{~m}$ and 7.3 - $10.3 \mathrm{~m}$. If these maxima represent periods of increased influx of locally-derived continental aerosols the most probable mechanism for this increase is an increase in the ice-free area from which the source is derived.

As a first approximation to the determination of a time-scale for the events suggested above and assuming very simplistically that Meserve

B Glacier has had a uniform vertical strain rate and a constant snow accumulation for the time period involved, the age ( $t$ in yrs) down the core can be computed using Haefeli (1961) such that:

$$
t=\frac{H}{\lambda} \ln \frac{H}{H-z}
$$

Where: $\mathrm{H}$ is total ice thickness

$\lambda$ is accumulation rate

2 is depth

(and all are expressed as ice equivalents in m)

Values employed in the computation included: (1) $\mathrm{H}=250 \mathrm{~m}$ based on our radio-echo sounding observation at the core site, (2) $\lambda=.051 \mathrm{~m}$

C using the mean value for the annual mass balance in the accumulation zone derived from observations made during the 1973-1974 balance year by Anderton and Fenwick (1976) and assuming a range in their values for the accumulation zone of .011 to .090 $m \mathrm{H}_{2} \mathrm{O}$ equivalents (the mean value we use closely approximates the $.056 \mathrm{~m} \mathrm{H}_{2} \mathrm{O}$ equivalent value they assigned to a site within meters of the core site) and (3) $z=18.12 \mathrm{~m}$ as the value of the core depth adjusted for a mean core density of $.64 \mathrm{gm} \cdot \mathrm{cm}^{-3}$. Using these values the age at the bottom of the core is approximately $370 \mathrm{yr}$.

Using the chronology determined for this core maxima in reactive silicate and iron occur in the age range 0 to approximating 100 yrs $B P$ and approximately 230 to 325 yr $\mathrm{BP}$. By comparison with the last 370 yrs. these two periods are times during which the terrain around Meserve Glacier and perhaps throughout all of the ice-free valleys of Southern Victoria Land was less ice-covered. Decreases in the ice cover in this region may have been due to a decrease in the extent of snowpatches, frozen lakes and/or glaciers.

\section{Acknowledgements}

Jon Hassinger and Peter Jeschke of the Department of Earth Sciences provided the chemical analyses referred to in the text. Todd Hinkley, USGS, Denver, offered several valuable criticisms. This research was supported by Division of Polar Programs NSF grant DPP78-21119 as part of a tuning exercise 
for studies now belng undertaken in Northern Victoria Land, Antarctica.

\section{References}

Anderson, P., and R. Fenwick, Dry valleys, Antarctica 1973-1974, N.Z. Hydrol. Res, Ann. Rpt. 37, 25 p., 1976.

Boutron, C., Reduction of contamination problems in sampling of Antarctic snows for trace element analysis, Anal. Chem. Acta, 106 127$130,1979$.

Boutron, C. and C. Lorius, Trace element content in East Antarctic snow samples, 1n Isotopes and Impurities in Snow and Ice, IAHS Publ. No. 118, 164-171, 1977.

Boutron, C. and C. Lorius, Trace metals in Antarctic snows since 1914, Nature, 277, 551-554, 1979.

Boutron, C. and S. Martin, Sources of twelve trace metals in Antarctic snows determined by principal component analysis, Jour. Geophys. Res., 85 5631-5638, 1980.

Boutron, C., M. Echevin and C. Lorius, Chemistry of polar snows. Estimation of rates of deposition in Antarctica, Geochim. Cosmochim. Acta, 36, 1029-1041, 1972.

Bull, C. and C.R. Carnein, The mass balance of a cold glacier: Meserve Glacier South Victoria Land, Antarctica, ISAGE Sypm., Hanover, N.H., U.S.A., 429-446, 1970.

Bulter, D., W.B. Lyons, J. Hassinger and P.A. Mayewski, Shallow core snow chemistry of Athabasca Glacier, Alberta, Can. Jour. Earth Sci., 17, 278-281, 1980.

Delmas, R., J.M. Ascencio and M. Legrand, Polar Ice evidence that $\mathrm{CO}_{2} 20,000 \mathrm{yr}$. B.P. was $50 \%$ of present, Nature, 284, 155-157, 1980.
Glibert, P.M, and T.C. Loder, Automated analysis of nutrients in sea water: A manual of techniques, W.H.O.I. Tech. Rpt. 77-47, 46p., 1977.

Haefeli, R., Contribution to the movement and the form of Ice sheets in the Arctic and Antarctic, Jour. of Glaciology, 3, 1133-1151, 1961.

Herron, M.M. and C.C. Langway, Jr., Dating of Ross Ice Shelf cores by chemical analysis, Jour. of Glaciology, 24, 345-357, 1979.

Johnson, B.B. and J.M. Chamberlain, Sodium, magnesium, potassium and calcium concentrations in ice cores from Law Dome, Antarctica Geochim. Cosmochim. Acta, 45, 771-776, 1981.

Mayewski, P.A., W.B. Lyons and N. Ahmad, Reconnissance glaciochemical studies in the Indian Himalayas, 38th Eastern Snow Conf., in press.

Stookey, L.L., Ferrozine-A new spectrophotomatric reactant from iron, Anal. Chem., 42, 779781,1970 .

Thompson, L.G. and E. Mosley-Thompson, Microparticle concentration variations linked with climate: Evidence from polar ice cores, Science, 212, 812-814, 1981.

Warburton, J.A. and G.0. Linkletter, Atmospheric process and the chemistry of snow on the Ross Ice Shelf, Antarctica, Jour. of Glaciology, 20, 149-162, 1978.

Warburton, J.A. and L.G. Young, Estimating ratios of snow accumulation in Antarctica by chemical methods, Jour. of Glaciology, 27, 347-357, 1981.

(Received November 4, 1981; accepted December $21,1981$. ) 